\title{
Comparison of Efficacy of Different Doses of Clonidine with $0.5 \%$ Bupivacaine for Spinal Anesthesia in Lower Limb Orthopedic Surgeries
}

\author{
${ }^{1} \mathrm{KT}$ Venkatesh Murthy, ${ }^{2}$ Maya D Nadkarni, ${ }^{3} \mathrm{~N}$ Amaranath
}

\begin{abstract}
Clonidine, a centrally acting $\alpha 2$ adrenergic agonist has been under use as an adjuvant with hyperbaric bupivacaine for prolonging analgesia and maintaining hemodynamic stability during lower limb orthopedic and lower abdominal surgeries.

The purpose of our study was to compare the efficacy and safety of intrathecal Clonidine 50 and $75 \mu \mathrm{g}$ as adjuvant to hyperbaric Bupivacaine $15 \mathrm{mg}(3 \mathrm{~mL})$, and hyperbaric Bupivacaine $3 \mathrm{~mL}$ with saline $0.5 \mathrm{~mL}$ for onset and duration of anesthesia, hemodynamic stability, and side effects if any.

This prospective randomized controlled study was conducted on 120 patients scheduled for lower limb orthopedic surgeries under spinal anesthesia. The study population was divided into three groups with 40 patients in each group. Group I (controlled group) received $3 \mathrm{~mL}(15 \mathrm{mg}$ ) of $0.5 \%$ Bupivacaine heavy and $0.5 \mathrm{~mL}$ of normal saline. Group II received $50 \mu \mathrm{g}$ of clonidine followed by Bupivacaine $0.5 \% 3 \mathrm{~mL}(15 \mathrm{mg})$ and group III received $75 \mu \mathrm{g}$ of clonidine followed by Bupivacaine $0.5 \% 3 \mathrm{~mL}(15 \mathrm{mg})$ intrathecally. Time taken for onset of sensory and motor blockade, duration of anesthesia, and any perioperative and postoperative complications was noted.

We found that clonidine $75 \mu \mathrm{g}$ given prior to bupivacaine, $3 \mathrm{~mL}$, significantly prolongs the duration of anesthesia with minimal changes in hemodynamic parameters and postoperative complications.
\end{abstract}

Keywords: Adjuvants, Bupivacaine heavy, Clonidine, Orthopedic surgeries, Spinal anesthesia.

How to cite this article: Murthy KTV, Nadkarni MD, Amaranath N. Comparison of Efficacy of Different Doses of Clonidine with $0.5 \%$ Bupivacaine for Spinal Anesthesia in Lower Limb Orthopedic Surgeries. J Med Sci 2017;3(2):45-49.

Source of support: Nil

Conflict of interest: None

\section{INTRODUCTION}

Spinal anesthesia is the most commonly employed regional anesthesia technique for lower abdominal and lower limb orthopedic surgeries. Analgesia and anesthesia are provided by the local anesthetics. Bupivacaine

\footnotetext{
${ }^{1}$ Professor, ${ }^{2}$ Associate Professor, ${ }^{3}$ Resident

${ }^{1-3}$ Department of Anesthesiology, RajaRajeswari Medical College \& Hospital, Bengaluru, Karnataka, India

Corresponding Author: KT Venkatesh Murthy, Professor Department of Anesthesiology, RajaRajeswari Medical College \& Hospital, Bengaluru, Karnataka, India, e-mail: ktv.murthy@gmail.com
}

is short lived and lasts from 120 to 200 minutes. Several drugs have been tried as adjuvants to bupivacaine to prolong analgesia and anesthesia. Clonidine, a selective alpha-2 adrenergic agonist, has been shown to prolong the sensory blockade and reduce the local anesthetic requirement and also reduction in postoperative analgesic requirement. It has been tried in different doses from 15 to $200 \mu \mathrm{g}$ either as adjuvant with different local anesthetics or sole anesthetic given intrathecally. ${ }^{1-13}$

In our study, we looked into the safety and efficacy of two doses of clonidine, 50 and $75 \mu \mathrm{g}$ given intrathecally as adjuvant, prior to hyperbaric Bupivacaine $0.5 \%$ administration in separate syringes, compared with injection hyperbaric Bupivacaine 0.5\% $15 \mathrm{mg}(3 \mathrm{~mL})+0.5 \mathrm{~mL}$ of normal saline given intrathecally. This was done with the view that mixing of these drugs changes the density of both the drugs affecting their spread in the cerebrospinal fluid. ${ }^{14-16}$

\section{MATERIALS AND METHODS}

After obtaining the Institutional Ethical Committee approval, this randomized double-blind study was conducted in our Anesthesia Department.

For the study, 120 patients between 20 and 70 years of age group belonging to American Society of Anesthesiologist (ASA) 1 and ASA 2 status undergoing lower limb major orthopedic surgeries, except replacement surgeries, were recruited. They were randomly divided into three groups of 40 patients each, using thick envelop method. Group I received plain bupivacaine heavy $0.5 \%$ $3 \mathrm{~mL}$ ( $15 \mathrm{mg}$ ) along with $0.5 \mathrm{~mL}$ of normal saline as adjuvant, group II received bupivacaine heavy $0.5 \% 3 \mathrm{~mL}$ with clonidine $50 \mu$ g as adjuvant, group III received bupivacaine heavy $0.5 \% 3 \mathrm{~mL}$ with clonidine $75 \mu \mathrm{g}$ as adjuvant for spinal anesthesia.

Patients having local infection at the injection site, spinal deformities, coagulopathies, hypersensitivity to drugs to be used, cardiovascular, renal, neurological and psychiatric disorders, patients on alpha adrenergic antagonists, $\mathrm{Ca}+$ channel blockers, angiotensin converting enzyme inhibitors, and those who refuse to give written consent were excluded from the study. Patient as well as the anesthesiologist administering spinal 
anesthesia and recording the parameters were blinded about the study drug used.

All the patients underwent preanesthetic evaluation on the previous day and Tab. Alprazolam $0.25 \mathrm{mg}$ was given orally on the night before surgery and kept nil orally for a minimum of 8 to 10 hours. On the day of surgery, patients were cannulated with 18G intravenous (IV) cannula and secured. Ringer's lactate I.V. fluid was started at the rate of $15 \mathrm{~mL} / \mathrm{kg} /$ hour. Injection Ondansetron $4 \mathrm{mg}$ and Ranitidine $50 \mathrm{mg}$ was given slowly through IV Basal heart rate (HR), noninvasive blood pressure, oxygen saturation, and electrocardiogram were recorded. Spinal anesthesia was administered under strict aseptic precaution at L3-L4 or L4-L5 space using 25G Quincke spinal needle. After obtaining clear and free flow of cerebrospinal fluid, normal saline $0.5 \mathrm{~mL}$, in group I, clonidine $50 \mu \mathrm{g}$ in group II, clonidine $75 \mu \mathrm{g}$ in group III were administered with a separate syringe just before injecting bupivacaine $15 \mathrm{mg}$ ( $3 \mathrm{~mL}$ ). Time taken for onset of sensory block was checked with cold gauze at L3 level and was taken as the time interval between intrathecal (IT) injection and loss of sensation to cold at the level below the umbilicus (L3). Time taken for onset of motor blockade was taken as interval between IT injection to Bromage scale 1 (patient is just unable to move the limb at hip joint), and time for complete block was taken as interval between IT injection and the complete loss of sensation and unable to move both the lower limbs (Bromage IV). Level of anesthesia was assessed by pinprick method. Duration of sensory block was taken as the interval between IT injection and two-level regression of block from the initial level. Duration of motor block was taken from onset of motor blockade to when the Bromage scale was 2 (patient was just able to move the ankle but unable to flex or move at the knee joint). Total duration of anesthesia was taken as time between the IT injection and complete recovery of sensory and motor blockade (Bromage scale 0 ). The duration of analgesia was defined as time interval between IT injection and first request for rescue analgesic by the patient. The highest level of sensory block was assessed by pinprick method. Injection diclofenac $3 \mathrm{mg} / \mathrm{kg}$ intramuscularly was used as postoperative analgesic.

Hemodynamic parameters like HR, systolic blood pressure (SBP), diastolic blood pressure, mean arterial pressure (MAP) were recorded at 5, 10, 20, 30, 60, 90, 120, $150,180,240,300$, and 360 minutes after spinal anesthesia.
Loss of blood more than $500 \mathrm{~mL}$ was substituted with transfusion of packed red blood cells or additional fluid (Ringer's lactate) depending on the preoperative hemoglobin concentration. Any drop in SBP below 80\% of the basal value, not responding to additional fluid of $300 \mathrm{~mL}$, was considered as hypotension, and treated with Injection Ephedrine $6 \mathrm{mg}$ bolus. Bradycardia was defined as $\mathrm{HR}<50 /$ minute and treated with aliquots of Injection Atropine $0.3 \mathrm{mg}$ bolus.

Any postoperative complications like nausea, vomiting, sedation, and hypotension were recorded and treated accordingly.

\section{RESULTS}

All the data collected were analyzed using Statistical Package for the Social Sciences version 15.0, SAS 9.2, Stata 10.1, R environment version 2.11.1 software. Analysis of variance (ANOVA) has been used to find the significance of study parameters between the groups. Chi-square/ Fisher's exact test has been used for analyzing categorical data. Significance was assessed at $5 \%(p<0.05)$ level of significance.

All the groups were comparable with no significant differences in the demographic characteristics like age, weight, and ASA grading. Time taken for onset of sensory block ( $3.93 \pm 1.00$ minutes in group I, $3.83 \pm 0.96$ minutes in group II, $3.68 \pm 0.62$ in group III with a p-value of 0.439 ) and motor blockade $(7.13 \pm 0.88$ minutes in group I, $7.00 \pm$ 0.82 minutes in group II, and $6.88 \pm 0.91$ minutes in group III with a p-value of 0.441) was comparable between the groups with slightly less in group III (Table 1) while the time taken for complete block was less in group III, which was strongly significant with a p-value of $<0.001$ (22.55 \pm 0.80 minutes in group I, $18.53 \pm 1.92$ minutes in group II, and $16.80 \pm 1.16$ minutes in group III) (Table 1). The level of sensory blockade was higher in group III compared with other groups $(\mathrm{p} \leq 0.001)$, with 14 patients having level at T5, 2 at T4, 11 at T7, and 13 at T8 in group III compared with 2 patients at T5, 13 at T7, and 25 at T8 in group I, and 3 patients at T5, 2 at T6, 17 at T7, and 18 at T8 level in group II and was also statistically strongly significant.

Though there was slight drop in the HR in all the groups between 30 and 120 minutes, there was no incidence of symptomatic bradycardia. The fall in HR was comparable between the groups and returned to near preanesthetic rate gradually after 120 minutes (Table 2).

Table 1: Comparison of study variables in three groups of patients studied using ANOVA test

\begin{tabular}{|c|c|c|c|c|}
\hline Variables & Group I & Group II & Group III & $p$-value \\
\hline Onset of sensory blockade (minutes) & $3.93 \pm 1.00$ & $3.83 \pm 0.96$ & $3.68 \pm 0.62$ & 0.439 \\
\hline Onset of motor blockade (minutes) & $7.13 \pm 0.88$ & $7.00 \pm 0.82$ & $6.88 \pm 0.91$ & 0.441 \\
\hline Time taken for complete block in minutes & $22.55 \pm 1.80$ & $18.53 \pm 1.92$ & $16.80 \pm 1.16$ & $<0.001^{*}$ \\
\hline Duration of surgery (minutes) & $171.85 \pm 42.13$ & $133.80 \pm 11.98$ & $147.93 \pm 16.16$ & $<0.001^{*}$ \\
\hline
\end{tabular}

*Moderately significant ( $p$-value $0.01-0.05)$ 
Comparison of Efficacy of Different Doses of Clonidine with $0.5 \%$ Bupivacaine for Spinal Anesthesia in Lower Limb

Table 2: Comparison of HR (bpm) in three groups of patients studied

\begin{tabular}{lllll}
\hline $\begin{array}{l}\text { Heart } \\
\text { rate } \\
\text { (bpm) }\end{array}$ & Group I & Group II & Group III & p-value \\
\hline 0 & $77.00 \pm 6.10$ & $77.80 \pm 5.30$ & $77.13 \pm 6.39$ & 0.811 \\
1 & $76.20 \pm 4.75$ & $75.73 \pm 4.44$ & $75.45 \pm 4.88$ & 0.770 \\
2 & $75.25 \pm 5.12$ & $75.40 \pm 4.80$ & $72.95 \pm 4.22$ & $0.038^{*}$ \\
3 & $71.93 \pm 4.71$ & $72.58 \pm 3.91$ & $70.10 \pm 3.30$ & $0.019^{*}$ \\
4 & $65.45 \pm 3.57$ & $66.85 \pm 3.42$ & $66.60 \pm 3.90$ & 0.189 \\
5 & $65.85 \pm 3.96$ & $67.05 \pm 2.78$ & $65.60 \pm 2.73$ & 0.101 \\
6 & $67.85 \pm 3.69$ & $68.15 \pm 2.72$ & $66.10 \pm 2.75$ & $0.007^{* *}$ \\
7 & $69.15 \pm 3.36$ & $69.20 \pm 2.67$ & $68.33 \pm 2.46$ & 0.310 \\
8 & $70.93 \pm 3.53$ & $70.85 \pm 2.07$ & $70.70 \pm 2.20$ & 0.930 \\
9 & $72.28 \pm 3.84$ & $70.80 \pm 1.68$ & $71.03 \pm 2.28$ & $0.039^{*}$ \\
10 & $74.05 \pm 4.14$ & $72.50 \pm 2.11$ & $71.65 \pm 2.07$ & $0.002^{* *}$ \\
11 & $74.90 \pm 4.10$ & $73.30 \pm 2.74$ & $71.80 \pm 2.43$ & $<0.001^{* *}$ \\
12 & $76.00 \pm 3.92$ & $74.33 \pm 2.25$ & $73.33 \pm 2.79$ & $0.001^{* *}$ \\
\hline
\end{tabular}

*Moderately significant ( $\mathrm{p}$-value $0.01-0.05) ;{ }^{* *}$ Highly significant ( $p$-value $<0.01$ )

A trend of fall in MAP was observed in all the groups between 20 and 120 minutes. The fall was more in groups II and III than in group I (Table 3). But only three patients in group I, five patients in group II, and eight patients in group III required vasopressor (Ephedrine $6 \mathrm{mg}$ bolus), while others responded to only fluid management for hypotension (Table 4).

Duration of sensory block was $189.55 \pm 6.05$ minutes in group I, $206 \pm 6.69$ minutes in group II, $234.40 \pm 8.59$ minutes in group III with a p-value of $<0.001$, which was

Table 4: Distribution and incidence of side effects in three groups of patients studied

\begin{tabular}{llllllll}
\hline \multirow{2}{*}{ Side effects } & \multicolumn{2}{c}{ Group I } & \multicolumn{2}{c}{ Group II } & \multicolumn{2}{c}{ Group III } \\
\cline { 2 - 3 } No. & $\%$ & & No. & $\%$ & & No. & $\%$ \\
\hline Nil & 37 & 92.5 & 35 & 87.5 & & 32 & 80.0 \\
Bradycardia +hypotension & 0 & 0.0 & 0 & 0.0 & 3 & 7.5 \\
Hypotension & 3 & 7.5 & 5 & 12.5 & 5 & 12.5 \\
\hline Total & 40 & 100.0 & 40 & 100.0 & 40 & 100.0 \\
\hline$p=0.232$, not significant; & Fisher's exact test & &
\end{tabular}

Table 3: Comparison of MAP ( $\mathrm{mm} \mathrm{Hg}$ ) in three groups of patients studied using ANOVA test

\begin{tabular}{lllll}
\hline $\begin{array}{l}\text { MAP } \\
(\mathrm{mm} \mathrm{Hg})\end{array}$ & Group I & Group II & Group III & p-value \\
\hline 0 & $90.64 \pm 5.41$ & $92.32 \pm 4.63$ & $89.70 \pm 4.99$ & $0.066^{+}$ \\
1 & $91.73 \pm 3.36$ & $92.93 \pm 2.75$ & $87.82 \pm 4.45$ & $<0.001^{*}$ \\
2 & $91.07 \pm 7.59$ & $92.05 \pm 2.97$ & $83.38 \pm 4.76$ & $<0.001^{*}$ \\
3 & $88.60 \pm 3.25$ & $88.83 \pm 2.87$ & $79.05 \pm 5.28$ & $<0.001^{*}$ \\
4 & $80.60 \pm 3.38$ & $80.25 \pm 4.53$ & $75.37 \pm 5.51$ & $<0.001^{*}$ \\
5 & $82.43 \pm 2.71$ & $82.57 \pm 3.70$ & $75.02 \pm 4.90$ & $<0.001^{*}$ \\
6 & $84.08 \pm 5.87$ & $85.22 \pm 1.79$ & $77.70 \pm 3.93$ & $<0.001^{*}$ \\
7 & $86.48 \pm 3.15$ & $87.97 \pm 2.53$ & $80.88 \pm 3.77$ & $<0.001^{*}$ \\
8 & $88.73 \pm 3.79$ & $89.58 \pm 2.67$ & $83.13 \pm 3.32$ & $<0.001^{*}$ \\
9 & $90.25 \pm 3.70$ & $91.18 \pm 2.22$ & $84.23 \pm 2.87$ & $<0.001^{*}$ \\
10 & $91.62 \pm 3.68$ & $92.58 \pm 2.48$ & $84.53 \pm 3.17$ & $<0.001^{*}$ \\
11 & $92.00 \pm 2.70$ & $92.78 \pm 7.60$ & $86.10 \pm 3.45$ & $<0.001^{*}$ \\
12 & $93.70 \pm 2.42$ & $93.79 \pm 1.70$ & $87.22 \pm 3.80$ & $<0.001^{*}$ \\
\hline
\end{tabular}

*Moderately significant (p-value $0.01-0.05)$; ${ }^{+}$Suggestive of significance ( $p$-value $0.05-0.01$ )

statistically strongly significant, and motor blockade was $202.10 \pm 6.55$ minutes in group I, $221.05 \pm 5.70$ minutes in group II, $345.38 \pm 7.04$ minutes in group III with a p-value of $<0.001$, which was also strongly significant. Total duration of analgesia was significantly prolonged in group III when compared with other groups (group I $=208.53 \pm 31.07$ minutes, group II $=236 \pm 98$ minutes, group $\mathrm{III}=368.90 \pm$ 8.27 minutes with a p-value of $<0.001$ ) (Table 5).

Postoperatively, three patients in group I, four patients each in groups II and III had nausea and vomiting, while only one patient had nausea in group II. Two patients each in groups I and II and three patients in group III had shivering, which was strongly statistically significant with a p-value of $<0.001$ (Table 6).

\section{DISCUSSION}

Clonidine, an alpha 2 adrenergic agonist, has been used extensively for its sedative and analgesic effects. It reduces the amount of local anesthetic agent required when used

Table 5: Comparison of duration of sensory/motor/total duration in three groups of patients studied using ANOVA test

\begin{tabular}{lllll}
\hline & Group I & Group II & Group III & $p$-value \\
\hline Duration of sensory block & $189.55 \pm 6.05$ & $206.83 \pm 6.69$ & $234.40 \pm 8.59$ & $<0.001^{*}$ \\
Duration of motor block & $202.10 \pm 6.55$ & $221.05 \pm 5.70$ & $345.38 \pm 7.04$ & $<0.001^{*}$ \\
Total duration of analgesia (minutes) & $208.53 \pm 31.07$ & $236.98 \pm 5.59$ & $368.90 \pm 8.27$ & $<0.001^{*}$ \\
\hline
\end{tabular}

*Moderately significant ( $p$-value $0.01-0.05)$

Table 6: Postoperative complications

\begin{tabular}{|c|c|c|c|c|c|c|}
\hline \multirow[b]{2}{*}{ Postoperative complications } & \multicolumn{2}{|c|}{ Group I $(n=40)$} & \multicolumn{2}{|c|}{ Group II $(n=40)$} & \multicolumn{2}{|c|}{ Group III $(n=40)$} \\
\hline & No. & $\%$ & No. & $\%$ & No. & $\%$ \\
\hline Nil & 35 & 87.5 & 33 & 82.5 & 33 & 82.5 \\
\hline Yes & 5 & 12.5 & 7 & 17.5 & 7 & 17.5 \\
\hline - Nausea and vomiting & 3 & 7.5 & 4 & 10.0 & 4 & 10.0 \\
\hline - Nausea & 0 & 0.0 & 1 & 2.5 & 0 & 0.0 \\
\hline - Shivering & 2 & 5.0 & 2 & 5.0 & 3 & 7.5 \\
\hline
\end{tabular}

$\mathrm{p}<0.001$; Significant; Fisher's exact test 
as an adjuvant during spinal anesthesia and prolongs the duration of analgesia compared with hyperbaric bupivacaine alone. It stimulates central inhibitory alpha 2 adrenoceptors to reduce central sympathetic outflow and norepinephrine release, leading to sedation, anxiolysis, and analgesia. It produces analgesia by depressing the release of C-fiber transmitters and hyperpolarization of postsynaptic dorsal horn neurons. It also prolongs the motor block by binding to motor neurons in the dorsal horn cells in the spinal column.

Many authors in the previous studies have used clonidine from 15 to $200 \mu \mathrm{g}$ as adjuvant to hyperbaric bupivacaine. But the dose of clonidine as an adjuvant which produces prolonged analgesia with minimal side effects has not been established.

In our study, we have tried to establish the efficacy of clonidine $50 \mu$ g (group II) and $75 \mu$ g (group III) given as adjuvant just prior to the administration of hyperbaric bupivacaine $15 \mathrm{mg}(3 \mathrm{~mL})$ compared with hyperbaric bupivacaine alone (group I) for spinal anesthesia in patients undergoing major lower limb orthopedic surgeries.

Clonidine, when combined with local anesthetic bupivacaine, potentiates the sympatholytic effect through inhibition of central sympathetic outflow and postsynaptic dorsal horn neurons, resulting in hypotension. Smaller dose of clonidine up to $75 \mu \mathrm{g}$ is not usually associated with systemic side effects like bradycardia, hypotension, or sedation.

We have observed in our study that the onset of sensory and motor blockade was comparable between all the three groups and was not significant with a p-value of 0.439 for sensory blockade and 0.441 for motor blockade. But the time taken for complete block was significantly less in group III with p-value of $<0.001$. Highest level of sensory blockade was achieved in group III (14 patients having blockade at $\mathrm{T} 5$ compared with 2 patients in group I and 3 patients in group II) with p-value of $<0.001$, which was statistically strongly significant. Mean duration of analgesia was also prolonged in group III compared with other two groups $(208.53 \pm 31.07$ minutes in group I, $236.98 \pm 5.59$ minutes in group II, and 368. $90 \pm 8.27$ minutes in group III) with $p$-value of $<0.001$, which was also strongly significant.

Slight fall in HR between 30 and 120 minutes was observed in all the groups, with group II and III showing relatively low HR compared with group I. But none required any active management for bradycardia. Though there was a trend of fall in MAP observed in all the groups between 20 and 120 minutes, only $7.5 \%$ (3 patients) in group I, $12.5 \%$ (5 patients) each in group II and III required injection Ephedrine $6 \mathrm{mg}$ I.V. bolus to treat hypotension. Three patients in group I, four patients each in groups II and III had postoperative nausea and vomiting, which was adequately treated, whereas two patients each in groups I and II and three patients in group III had postoperative shivering. Sedation, a central effect of alpha 2 adrenergic drugs, was not observed in any of the groups.

Previous studies have shown that increase in the dose of IT clonidine from 50 to $150 \mu \mathrm{g}$ increases the duration of analgesia in a dose-dependent manner but increasing the dose more than $75 \mu \mathrm{g}$ also increases the incidences of bradycardia, hypotension, and postoperative sedation. ${ }^{1-6}$

\section{CONCLUSION}

Intrathecal clonidine has been known to increase the duration of sensory and motor block with excellent postoperative analgesia. In our study we have found that Injection clonidine 50 and $75 \mu$ given intrathecally prior to Injection bupivacaine $15 \mathrm{mg}$ causes prolonged analgesia compared with bupivacaine alone. Analgesia provided by clonidine $75 \mu \mathrm{g}$ as an adjuvant to bupivacaine $15 \mathrm{mg}$ significantly prolongs the duration of analgesia with hemodynamic stability compared with $50 \mu \mathrm{g}$.

\section{LIMITATIONS}

We have not calculated the drug dosage as per the height and weight of the patients which might have given better variations in the hemodynamic response and postoperative complications.

\section{REFERENCES}

1. Filos KS, Goudas LC, Patroni O, Polyzou V. Hemodynamic and analgesic profile after intrathecal Clonidine in humans. A dose-response study. Anesthesiology 1994 Sep;81(3):591-601.

2. Niemi L. Effects of intrathecal clonidine on duration of bupivacaine spinal anaesthesia, haemodynamics, and postoperative analgesia in patients undergoing knee arthroscopy. Acta Anesthesiol Scand 1994 Oct;38(7):724-728.

3. Kaabachi O, Zarghouni A, Ouezini R, Abdelaziz AB, Chattaoui O, Kokki H. Clonidine $1 \mathrm{microg} / \mathrm{kg}$ is a safe and effective adjuvant to plain bupivacaine in spinal anesthesia in adolescents. Anesth Analg 2007 Aug;105(2):516-519.

4. Kiran S, Kumar R. Evaluation of intrathecal Clonidine as adjuvant to hyperbaric Bupivacaine for spinal anaesthesiaquest for the optimal dose. Indian J Basic Appl Med Res 2016 Sep;5(4):324-333.

5. Strebel S, Gurzeler JA, Schneider MC, Aeschbach A, Kindler CH. Small-dose intrathecal clonidine and isobaric bupivacaine for orthopedic surgery: a dose-response study. Anesth Analg 2004 Oct;99(4):1231-1238.

6. Dobrydnjov I, Axelsson K, ThörnSE,Matthiesen P,KlockhoffH, Holmström B, Gupta A. Clonidine combined with small-dose bupivacaine during spinal anesthesia for inguinal herniorrhaphy: a randomized double-blinded study. Anesth Analg 2003 May;96(5):1496-1503. 
7. Sethi BS, Samuel M, Sreevastava D. Efficacy of analgesic effects of low dose intrathecal clonidine as adjuvant to bupivacaine. Indian J Anaesth 2007;51(5):415-419.

8. Heo GJ, Kim YH, OH JH, Joo JC. Effect of intrathecal clonidine in hyperbaric bupivacaine spinal anesthesia. Korean J Anesthesiol 1997;33:304-308.

9. Saxena H, Singh S, Ghildiyal S. Low dose intrathecal Clonidine with bupivacaine improves onset and duration of block with hemodynamic stability. Internet J Anesthesiol 2010;23(11):9137.

10. Polaiah M.D., Dr. Venugopala Rao. The effects of clonidine with bupivacaine in spinal anaesthesia to lower limb orthopedic surgery cases: a retrospective cohort study. J Dent Med Sci 2015;14(3):31-34.

11. Sapate M, Sahu P, Shah B, Suryawanshi C, Kulkarni A, Panditrao MM. Evaluation of bupivacaine-clonidine combination for unilateral spinal anesthesia in lower limb below-knee orthopedic surgery. Saudi J Anaesth 2014 Jul;8(3):384-387.

12. Elia $N$, Culebras $X$, Mazza $C$, Schiffer E, Tramèr MR. Clonidine as an adjuvant to intrathecal local anesthetics for surgery: systematic review of randomized trials. Reg Anesth Pain Med 2008 Mar-Apr;33(2):159-167.

13. Dobrydnjov I, Alxelsson K, Gupta A, Lundin A, Holmström B. Improved analgesia with clonidine when added to local anesthetic during combined spinal-epidural anesthesia for hip arthroplasty: a double-blind, randomized and placebocontrolled study. Acta Anaesthesiol Scand 2005 Apr;49(4): 538-545.

14. Baker A, Klimscha W, Eisenach JC, Li XH, Wildling E, MenthChiari WA, Chiari AI. Intrathecal clonidine for postoperative analgesia in elderly patients: the influence of baricity on hemodynamic and analgesic effects. Anesth Analg 2004 Jul;99(1):128-134.

15. Mandal SK, Biswas MR, Mondal SK, Das A, Das K. Intrathecal clonidine co-administered with hyperbaric bupivacaine in infra-umbilical surgery-a dose response study. Anal Int Med Dent Res 2016;2(6):27-32.

16. Sachan P, Kumar N, Sharma JP. Intrathecal clonidine with hyperbaric bupivacaine administered as a mixture and sequentially in caesarean section: a randomized controlled study. Indian J Anaesthesia 2014 May-Jun;58(3):287-292. 